\title{
Article Title: Location or Insolation: the importance of siting in emissions mitigation from solar photovoltaics
}

\author{
Article Type: Focus Article
}

\section{Authors:}

First author

Jeremiah X. Johnson

Center for Sustainable Systems

School of Natural Resources \& Environment

University of Michigan

$+17347633243$

\begin{abstract}
Achieving environmental benefits is often a primary motivation for integrating renewable energy into the grid. The magnitude of generation from a solar power project is influenced by the solar resource quality, but locations with high insolation do not necessarily yield the greatest emissions reduction benefits. This study simulates the power system response to ten identical solar projects in different regions across the United States, selected to represent a wide range of solar resource quality and power grid configurations. The power grid mix is often a key determinant in offsetting $\mathrm{CO}_{2}, \mathrm{SO}_{2}$, and $\mathrm{NO}_{x}$ emissions, illustrating how lower quality solar resources can be more effective than sunnier sites at emissions mitigation when one considers characteristics of the power grid. The analysis shows a strong relationship between emissions mitigation and the share of offset generation that is coal-fired. The strongest correlation is shown for $\mathrm{CO}_{2}$; the presence or absence of emissions control equipment and the sulfur content of the coal complicates the relationship for $\mathrm{SO}_{2}$ and $\mathrm{NO}_{\mathrm{x}}$. The emissions intensity of offset generation is insensitive to whether the solar project is fixed tilt or single-axis tracking. When seeking to mitigate power sector emissions, the impacts of solar design considerations on the temporal profile of generation are less important than the overall amount of generation and the location of interconnection. Public policies that target only the magnitude of generation from renewables (e.g., many Renewable Portfolio Standards) or the installed cost (e.g., the Investment Tax Credit) will likely lead to suboptimal emissions mitigation.
\end{abstract}

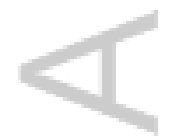

This is the author manuscript accepted for publication and has undergone full peer review but has not been through the copyediting, typesetting, pagination and proofreading process, which may lead to differences between this version and the Version of Record. Please cite this article as doi: 10.1002/wene.249

This article is protected by copyright. All rights reserved. 


\section{Introduction}

One of the primary motivations for the expansion of renewable generation is to reduce emissions and the environmental impact from the power system. Variable renewables, namely wind and solar power, generate when the resource is available and must be balanced by dispatchable generators or flexible load on the grid. When considering the desirability of variable renewable projects, resource quality is a common metric deployed (e.g., solar irradiance and wind speed distribution). While resource quality is a key determinant for the magnitude of electricity that the project with produce, it is not the only factor that will determine the environmental benefits of a project.

The grid characteristics, load profiles, and the seasonal and diurnal shapes of generation are also important considerations for emissions reduction. The marginal emissions factor for a region varies over time, determined by these grid characteristics. ${ }^{1}$ Integrating variable renewables into a grid dominated by natural gas generation will likely yield less of an environmental benefit than integration into a coaldominated grid.

This article reviews research on the relative importance of the location of interconnection for emissions mitigation from a renewable project. In addition, emissions mitigation from $10 \mathrm{MW}_{\mathrm{dc}}$ of solar photovoltaics is quantified at ten U.S. locations. These sites were selected to represent a wide range in solar resource quality and regional power grid characteristics.

Other studies have investigated the impact of variables renewables on power system emissions. In 2013, Siler-Evans et al. examined the magnitude of emissions reductions for wind and solar to show regional disparities in impacts, with some lower quality sites yielding greater health and environmental benefits. $^{2}$ In a working paper, Callaway et al. also estimate that emissions-related benefits from renewable energy and energy efficiency account for between one-quarter and one half of the total value generated, with important regional variations. ${ }^{3}$ Valentino et al. used a unit commitment and economic dispatch model to assess the emissions impacts of increasing penetrations of wind generation in a single region (Illinois) to highlight the impact of emissions from power plant cycling and start-up. ${ }^{4}$ These studies underscore the importance of siting a renewable project and power system characteristics on the outcomes for emissions reduction.

Several other studies have examined the economic benefits of emissions reduction attributable to the introduction of renewable generation. Cullen estimated emissions reductions from wind in Texas, showing that production subsidies are often not justified on the basis of the social cost of pollution alone. ${ }^{5}$ Kaffine et al. also estimated emissions reductions in Texas, finding that substantial variation in reduction exists, strongly driven by the generation mix. ${ }^{6}$ In demonstrating that renewable generation is 
not a homogenous good, Novan illustrated how different options yield heterogeneous environmental benefits per unit of generation. ${ }^{7}$ In a recent paper, Chiang et al. examined the role of siting decisions in the value of mitigated emissions from offshore wind, estimating both resource quality and abatement value. $^{8}$

Understanding regional disparities in emissions rates is an essential component of effectively mitigating harm. Kerl et al. coupled a reduced form atmospheric model with a unit commitment and economic dispatch model to show how considering such regional disparities and air quality outcomes can inform changes in operations. They demonstrated that understanding the spatial distribution of impacts could be used could inform dispatch, yielding net benefits when pollution damage costs are considered. ${ }^{9}$

In a comprehensive review, Ryan et al. examined the wide variety of models and methods that have been developed to calculate grid electricity emissions, finding that it is imperative to match the method to the research question and grid characteristics at hand. ${ }^{10}$ Methods range from simple emissions factors (e.g., the U.S. Environmental Protection Agency's eGRID database of average and non-baseload emissions factors ${ }^{11}$ ) to more complex statistical relationships between load and emissions (e.g., Graff Zivin et al. ${ }^{12}$ ). Determining the grid electricity emissions is relevant not only to the integration of renewable energy, but also for estimating the emissions impacts to changes in load driven by efficiency measures (i.e., decreases in load) or new sources of demand (i.e., increases in load). For example, much attention has been paid to the emissions impacts associated with electric vehicles (e.g., Tamayao et al.., ${ }^{13}$ MacPherson et al. ${ }^{14}$ ).

This focus article further examines the question: What is the importance of grid characteristics in emissions reduction from solar PV, relative to the role of solar resource quality. The analysis presented here extends past efforts by examining more contemporary data (2015), changes to offset emissions intensity over time (2007 through 2015), different solar project configurations (fixed v. tracking), and different regional definitions.

\section{METHODS}

Ten sites were selected to illustrate diverse power system characteristics and solar resource quality, subject to availability of Typical Meteorological Year 3 (TMY3) data. ${ }^{15}$ TMY data provides the most representative weather data for a given station, including solar radiation and temperature. Figure 1 shows the location of these ten sites. 
The hourly output from the solar projects are simulated using the U.S. National Renewable Energy Laboratory's (NREL's) System Advisor Model, ${ }^{16}$ under both fixed tilt and single axis tracking design. For the fixed tilt systems, the system design and key assumptions include $10 \mathrm{MW}_{\mathrm{dc}}$ of First Solar FS-4100 modules, a DC-to-AC ratio of 1.2 with an AE Solar Energy 5.0 inverter, and 5.4\% power losses. The projects are designed with fixed tilt equal to latitude and a due south orientation. Row spacing to set to achieve a ground cover ratio of 0.3 to minimize self-shading and it is assumed that the projects do not experience curtailment. The single-axis tracking system design uses Sun Power E20-327 modules, with a horizontal east-west tracking system, a rotational capability of $75^{\circ}$ from center, and optimized backtracking to mitigate shading impacts. The selection of thin film for the fixed axis and crystalline silicon for the tracking configuration is consistent with recent trends in U.S. solar development. ${ }^{17}$

The hourly generation profiles for each of the sites are then coupled with the Avoided Emissions and geneRation Tool (AVERT) developed for the U.S. Environmental Protection Agency. ${ }^{18}$ This model calculates the emissions impacts of displaced generation upon introduction of renewable energy and energy efficiency projects, relying on historical relationships between past generation, heat input, and emissions. The results have an hourly temporal resolution specific to each of ten regions across the continental U.S. For this analysis, one solar location was selected for each of AVERT's ten regions, with grid data from 2015.

The total annual emissions reduction $(M)$ is represented by Eq. 1:

$$
M=\sum_{i=1}^{8,760} E I_{i} \cdot G_{i} \quad \text { Eq. } 1
$$

where $E I_{i}$ is the emissions intensity of offset generation (metric tons or kg of pollutant offset per MWh of solar generation) in hour $i$ and $G_{i}$ is the solar generation (MWh) in hour $i$. This simple relationship is useful to illustrate the importance of matching emissions intensities with renewable generation on a temporally resolved basis to accurately represent total emission reductions.

\section{ROLE OF SITING IN EMISSIONS MITIGATION}

As expected, the selected sites with a higher typical solar insolation yielded more solar generation and higher system capacity factors. Table 1 shows the annual project generation for each of the selected sites and the associated capacity factor for both the fixed tilt and single-axis tracking configurations. Capacity factors are calculated as the ratio of project output (ac terms) to the maximum module production (dc rated capacity), consistent with the approach used by the U.S. National Renewable Energy Laboratory's System Advisor Model. The results in Table 1 show the importance of solar resource quality, with the highest producing site (Phoenix, Arizona) yielding over $60 \%$ more generation 
than the lowest producing site (Seattle, Washington). Shifting from fixed tilt to single-axis tracking increases the annual generation between $18 \%$ and $24 \%$, depending on the location.

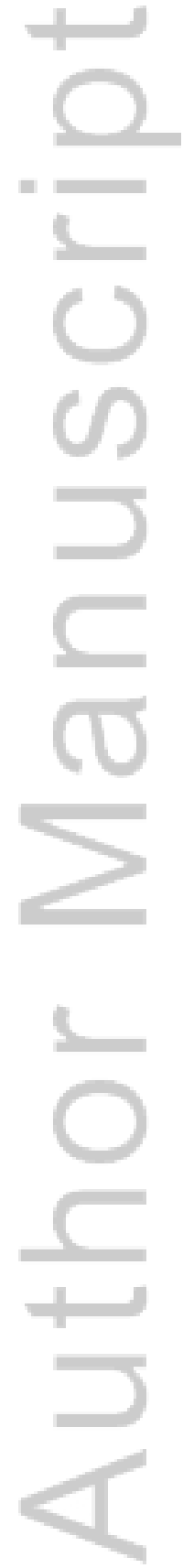

This article is protected by copyright. All rights reserved. 
The mitigation of emissions, however, is not simply determined by the annual solar generation. The emissions intensity of offset generation is also a key determinant in total emissions reductions. Figure 2a shows the results for $\mathrm{CO}_{2}$ mitigation upon the introduction of the $10 \mathrm{MW}_{\mathrm{dc}}$ fixed tilt solar project in each of the ten selected locations. The color of each region represents the average offset emissions intensity in terms of tons of $\mathrm{CO}_{2}$ per $\mathrm{MWh}$ of solar generation. These values are specific to the generation profile for the given solar project (i.e., the time of day of the generation) and represent the net emissions associated the change in generation due to the introduction of the solar, as a function of the magnitude of generation. The white bars in Figure 2a represent the total annual reduction in emissions at each site. These results show that the best solar resources do not, in fact, lead to the highest $\mathrm{CO}_{2}$ mitigation.

Figure $2 \mathrm{~b}$ shows the results for offset $\mathrm{SO}_{2}$ emissions intensity and total annual $\mathrm{SO}_{2}$ mitigation for each of the sites. These results demonstrate an even greater disparity across the regions, with the offset $\mathrm{SO}_{2}$ emissions intensity ranging from $30 \mathrm{~g} \mathrm{SO}_{2} / \mathrm{MWh}$ in California to $1.5 \mathrm{~kg} \mathrm{SO}_{2} / \mathrm{MWh}$ in Ohio. The regional disparities shown in Figure $2 \mathrm{~b}$ are driven by different sulfur contents of coal that are predominantly used in each region, the prevalence of flue gas desulfurization, and, more generally, the share of offset generation attributable to coal. Figure $2 \mathrm{c}$ shows the results for $\mathrm{NO}_{\mathrm{x}}$ emissions. Compared to $\mathrm{SO}_{2}$ emissions, the range of outcomes for offset $\mathrm{NO}_{\mathrm{x}}$ emissions is considerably smaller, with the offset emissions intensities ranging from 230 to $690 \mathrm{~g} \mathrm{NO}_{x} / \mathrm{MWh}$. Again, we see that the sites with the largest emissions reductions are not necessarily those with the superior solar resource.

To illustrate the role of both the solar capacity factor and the offset emissions intensity, Figure 3 shows the results for each site in the context of the total offset emissions per unit of installed capacity. The $x-$ axis represents solar resource quality (i.e., the project's capacity factor); the $y$-axis represents the offset emissions intensity of the grid, and the bands of solid colors represent the total annual offset emissions per unit of installed solar capacity. These figures illustrate that greater emissions reductions can be achieved with higher resource quality, offsetting higher polluting generation, or both.

Figure 3a shows that some of the solar projects that resulted in the lowest offset $\mathrm{CO}_{2}$ emissions had mid-range (e.g., MA) or even high (e.g., CA) capacity factors, but their effectiveness in reducing emissions was limited by the relatively low carbon intensity of the offset emissions. The sites that reduced the greatest total $\mathrm{CO}_{2}(\mathrm{IA}, \mathrm{KS}$, and $\mathrm{CO})$ were all sites that yielded mid-range capacity factors but offset highly carbon-intensive generation. 
As shown in Figure $3 \mathrm{~b}$, the solar resource quality is not a key driver in the reduction of $\mathrm{SO}_{2}$ emissions. The mitigation of $\mathrm{SO}_{2}$ by solar is largely determined by the grid characteristics, namely the regions in the U.S. that have a higher share of generation from high-sulfur coal. The solar site examined in Ohio offsets generation with a considerably higher $\mathrm{SO}_{2}$ emissions intensity than the other sites, yielding far greater total $\mathrm{SO}_{2}$ reductions despite the poor solar resource quality. The solar projects in the western U.S. including Colorado, California, and Arizona offset very little $\mathrm{SO}_{2}$, despite the high solar capacity factors, due to the low $\mathrm{SO}_{2}$ emissions intensity of the grid in those regions.

Figure 3c illustrates that both solar resource quality and the region's offset emissions intensity are both determinants in the magnitude of $\mathrm{NO}_{\mathrm{x}}$ emissions reductions. Both coal and natural gas generation emit $\mathrm{NO}_{x}$, although coal-fired generation typically has higher $\mathrm{NO}_{x}$ emissions rates. ${ }^{19}$ We see in Figure $3 \mathrm{c}$ that the sites with the greatest overall $\mathrm{NO}_{x}$ emissions are those with high offset emissions intensity (e.g., $\mathrm{OH}$, $\mathrm{IA}, \mathrm{KS}$ ), those with the best solar quality (e.g., AZ), and both (e.g., CO).

Figures 2 and 3 examine the impact of a $10 \mathrm{MW}_{\mathrm{dc}}$ fixed tilt solar installation. As reported in Table 1, moving from a fixed tilt configuration to a single-axis tracking system would increase generation by $18 \%$ to $24 \%$. The horizontal axis tracking system modeled allows for east-west tracking, which serves to decrease the angle of incidence and increase generation throughout the day. This increased generation serves to offset more fossil-fuel fired generation, thereby reducing overall emissions.

As shown in Figure 4, the introduction of the tracking system increases the projects' capacity factor, although the magnitude of that increase varies by location. The altered diurnal profiles of these projects are not found to have a meaningful impact on the offset emissions intensity. Across all ten sites, the offset emissions intensity changed by less than $2 \%$ for $\mathrm{CO}_{2}$ (Figure 4a), $\mathrm{SO}_{2}$ (Figure $4 \mathrm{~b}$ ), and $\mathrm{NO}_{x}$ (Figure 4c), as shown by the near-horizontal lines from fixed tilt to single-axis tracking. This suggests that, when seeking to mitigate power sector emissions, the impacts of solar design considerations on the temporal profile of generation are less important than the overall amount of solar generation and the location of interconnection.

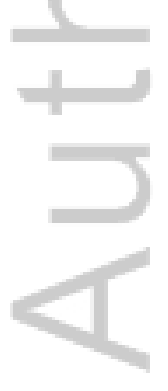

This article is protected by copyright. All rights reserved. 
The offset emissions intensity for each of the three pollutants is largely driven by share of coal generation that is displaced, as determined by the AVERT model. Figure 5 explores the relationship between the emissions intensity of offset generation and the proportion of coal generation offset to total solar generation. In Figure $5 \mathrm{a}$, we see a strong correlation between $\mathrm{CO}_{2}$ offset emissions intensity and the proportion of offset generation that is coal. The linear trend line suggests that solar which offsets no coal generation $(x=0)$ would yield an offset emissions intensity of $0.45+\mathrm{CO}_{2} / \mathrm{MWh}$, a value that is representative of emissions from a moderately efficient natural gas plant. At the other end of the spectrum, offsetting coal alone $(x=1)$ would yield an offset emissions factor of $0.91 \mathrm{t} \mathrm{CO}_{2} / \mathrm{MWh}$, over twice as high.

As shown in Figure $5 b$, the correlation between the offset $\mathrm{SO}_{2}$ emissions intensity and the proportion coal generation offset is not as strong as the comparable relationship for $\mathrm{CO}_{2} . \mathrm{SO}_{2}$ emissions are driven predominately by coal generation, but the emissions from a given plant can vary greatly based on the sulfur content of the coal and the presence or absence of emissions controls equipment (e.g., flue gas desulfurization).

Figure $5 \mathrm{c}$ shows the correlation between offset $\mathrm{NO}_{\mathrm{x}}$ emissions intensity and the proportion coal generation offset. Both coal and natural gas generation lead to thermal $\mathrm{NO}_{\mathrm{x}}$, while coal generation also emits fuel $\mathrm{NO}_{\mathrm{x}}{ }^{19}$ Emissions control technologies and operational strategies at these plants can reduce emissions, leading to a wide range of emissions factors for a given plant type. Despite this complicating factor, this analysis does show a clear upward trend, with more $\mathrm{NO}_{\mathrm{x}}$ reduction achieved when more coal generation is displaced.

Figure 6 shows the changes in the offset emissions intensity from fixed tilt solar generation over time, from 2007 through 2015. As is shown in Figure 6a, the offset $\mathrm{CO}_{2}$ emissions intensity did not change substantially during this period of time, with many regions resulting in a net increase on the $\mathrm{CO}_{2}$ intensity of offset generation. From 2007 to 2015, the net changes in offset $\mathrm{CO}_{2}$ emissions intensity ranged from decreases of $3 \%$ to increases of $13 \%$. During this same time period, overall $\mathrm{CO}_{2}$ emissions from electricity generation in the U.S. dropped $21 \%$, while total generation only decreased $1.9 \%,{ }^{20}$ yielding a decrease in the sector-wide $\mathrm{CO}_{2}$ emissions intensity of $19.6 \%$. This marked decrease in total $\mathrm{CO}_{2}$ emissions intensity stands in stark contrast to the increases or modest decreases in changes in $\mathrm{CO}_{2}$ offset emissions intensity from solar generation. Solar generation occurs during daylight hours and offsets marginal generation. The changes occurring in the power sector, such as the addition of wind 
and solar generation and the shift from coal to natural gas generation, appear to have not decreased the marginal emissions intensity during hours of solar generation.

Figure $6 \mathrm{~b}$ shows that the offset $\mathrm{SO}_{2}$ emissions intensity from solar generation did, for many regions, decrease considerably. While some regions with very low $\mathrm{SO}_{2}$ emissions factors saw a net increase (e.g., $\mathrm{CA}$ and $\mathrm{AZ}$ ), the regions with the highest $\mathrm{SO}_{2}$ factors saw large declines, with $\mathrm{OH}, \mathrm{IA}$, and $\mathrm{GA}$ decreasing by over $50 \%$. These decreases were driven by acid rain regulations that required flue gas desulfurization or the use of low sulfur fuels. Figure $6 \mathrm{c}$ shows near universal decreases in the offset $\mathrm{NO}_{\mathrm{x}}$ emissions intensity from solar generation. Nine out of ten regions saw a decrease in values, with an average decrease of $22 \%$.

\section{CONCLUSIONS}

This analysis demonstrated that power grid characteristics can play an important role in the environmental benefits of a grid-connected solar project. Two identical solar projects sited in different locations can, and likely would, yield vastly different levels of emissions reduction. Because a commonly stated goal of increasing the share of renewables on the grid is to reduce environmental impacts, it is essential to consider the context and power system characteristics into which a solar project is being integrated.

In the U.S., public policy that seeks to increase renewable generation typically does not consider the importance of power grid characteristics and the offset emissions intensity. Among the most important and effective public policies to support renewables have been state-level Renewable Portfolio Standards (RPS). While they vary by state, a typical design for an RPS is to set a percent of electricity sales that must be met by qualified renewable generation. While such a design has led to increased renewable generation and environmental benefits ${ }^{21} 22$, there are two key reasons why these policies may not maximize the offset emissions from new renewables. First, the states that have enacted RPS policies are not necessarily those with the highest grid emissions intensities. Research has shown that a key driver for the enactment of an RPS is a state's political ideology or private interests, not necessarily environmental benefits or job creation. ${ }^{23}$ That said, despite the fact that it may be more cost effective to mitigate emissions by funding renewable energy in another state, such efforts may be politically untenable due to the expectation of the development of local resources. Secondly, the design of most RPS policies set renewables targets as a share of retail sales. To achieve these targets, load serving entities do not need to consider the type of generation that is being offset. The marginal emissions factor for a region may be significantly higher during offpeak hours making wind more effective at emissions mitigation, but that information would be irrelevant to successfully meeting the targets of the RPS under such a design. By the nature of their design, the fact that they are state-level policies, and 
the multiple objectives that they may be seeking to meet, RPS policies can be sub-optimal means of deploying renewables to reduce emissions.

Other U.S. policies designed to encourage the development of renewables provide financial incentives. Solar development has been incentivized by both the investment tax credit (ITC) and accelerated depreciation schedules. The ITC provides developers with a tax credit equal to set percentage of the qualified investment costs of the solar project, while accelerated depreciation allows businesses to deduct the depreciable basis of a project over a shorter time frame. These incentives have been critical to many projects' viability, but are awarded based on project costs and blind to the emissions reduction benefits.

Many analyses of the environmental impacts of changes to power system simply assume a "grid average" emissions intensity. ${ }^{10}$ As illustrated in Ryan et al., this approach is not appropriate when the research question seeks to understand the impact of a "change in" grid operations. Average emissions factors include generation from nuclear and renewables - generation types that are typically not offset by the introduction of new solar generation. Understanding the consequential impacts and the net change in emissions as we have done here is essential to effectively characterize the environmental benefits of a solar project.

This study examines emissions impacts from solar photovoltaics over the past decade. It is also important to consider future changes to grid infrastructure when discussing the long term environmental implications of a solar project. If current U.S. trends continue and we see coal plant retirements far outpacing any new coal development, we may expect the offset emissions intensity for each of the regions to move toward the emissions intensity for a natural gas plant. If this occurred, this would require more installed solar capacity to displace the same amount of emissions.

As illustrated for the period of 2007 through 2015 for $\mathrm{CO}_{2}$ emissions, however, decreasing sector-wide emissions intensities do not necessary yield a direct relationship to the offset emissions from solar generation. Despite a nearly $20 \%$ decrease in the overall $\mathrm{CO}_{2}$ emissions intensity from U.S. electricity production, the offset emissions intensity attributable to solar generation increased in many regions. This is likely due to the fact that the key drivers that pushed down the overall emissions intensity, such as the introduction of wind and solar power, as well as coal-to-gas switching, did not change the marginal emissions intensity during hours of solar generation in the same direction or magnitude.

This study demonstrated that different diurnal profiles between fixed tilt and single-axis tracking had little impact on the offset emissions intensity of the grid. This result may be reasonably extended to 
other solar project design considerations, such as the recent trend of increasing inverter loading ratios. ${ }^{24}$ Increasing the inverter loading ratio (i.e., the ratio of dc module capacity to ac inverter capacity) serves to "flatten out" mid-day generation yielding a diurnal profile that is similar to east-to-west single-axis tracking. ${ }^{25}$ Further research is needed to better understand the impacts of other solar project design considerations, as well as the impacts from introducing energy storage or wind power.

While solar resource quality is a key driver to determine generation, which in turn influences emissions mitigation, the role of project siting and regional grid characteristics are often overlooked when considering the environmental merits of a renewable project. Siting and the time of day of solar generation are also determinants of the value of the offset energy and the economic attractiveness of potential projects. By coupling the findings on offset emissions, as shown in this study, with economic analysis that quantifies the net change in system costs due to the project, we can calculate the cost of emissions mitigation. Such analyses would determine the most cost effective means of reducing emissions through the use of new solar generation. Current policies that focus solely on the magnitude of renewable generation or the installed cost of renewable projects are likely inefficient means to reduce system-wide emissions. Renewed attention to siting and particular attention to the grid configuration at the point of interconnection could ensure that more informed decisions are made with respect to the emissions mitigation potential of solar power.

Table 1: Annual solar generation from a $10 \mathrm{MW}_{\mathrm{dc}}$ project at ten sites, with either fixed tilt set at latitude or single-axis tracking

\begin{tabular}{|c|c|c|c|c|c|}
\hline \multirow{2}{*}{ Site } & \multirow[t]{2}{*}{$\begin{array}{c}\text { Station } \\
\text { Identification }\end{array}$} & \multicolumn{2}{|c|}{ Fixed Tilt at Latitude } & \multicolumn{2}{|c|}{ Single-Axis Tracking } \\
\hline & & $\begin{array}{l}\text { Annual } \\
\text { Generation } \\
\left(\mathrm{MWh}_{\mathrm{ac}} / \mathrm{yr}\right)\end{array}$ & $\begin{array}{l}\text { Capacity } \\
\text { Factor (\%) }\end{array}$ & $\begin{array}{l}\text { Annual } \\
\text { Generation } \\
\left(\text { MWh }_{\mathrm{ac}} / \mathrm{yr}\right)\end{array}$ & $\begin{array}{l}\text { Capacity } \\
\text { Factor (\%) }\end{array}$ \\
\hline Seattle, WA & 727930 & 12,100 & $13.8 \%$ & 14,400 & $16.5 \%$ \\
\hline Cleveland, $\mathrm{OH}$ & 725240 & 13,000 & $14.8 \%$ & 15,300 & $17.5 \%$ \\
\hline Boston, MA & 725090 & 14,300 & $16.4 \%$ & 17,000 & $19.4 \%$ \\
\hline Des Moines, IA & 725460 & 15,400 & $17.6 \%$ & 18,800 & $21.4 \%$ \\
\hline Topeka, KS & 724560 & 15,600 & $17.8 \%$ & 19,000 & $21.7 \%$ \\
\hline Atlanta, GA & 722190 & 15,800 & $18.1 \%$ & 18,800 & $21.5 \%$ \\
\hline Dallas, TX & 722590 & 16,600 & $19.0 \%$ & 20,100 & $22.9 \%$ \\
\hline Denver, CO & 725650 & 16,900 & $19.3 \%$ & 20,700 & $23.6 \%$ \\
\hline San Diego, CA & 722900 & 18,100 & $20.6 \%$ & 21,600 & $24.7 \%$ \\
\hline Phoenix, AZ & 722780 & 19,500 & $22.2 \%$ & 24,200 & $27.6 \%$ \\
\hline
\end{tabular}




\section{REFERENCES}

1. Siler-Evans, K., Azevedo, I. L. \& Morgan, M. G. Marginal emissions factors for the US electricity system. Environ. Sci. Technol. 46, 4742-4748 (2012).

2. Siler-Evans, K., Azevedo, I. L., Morgan, M. G. \& Apt, J. Regional variations in the health, environmental, and climate benefits of wind and solar generation. Proc. Natl. Acad. Sci. 110, 1176811773 (2013).

3. Callaway, D., Fowlie, M. \& McCormick, G. Location, location, location: The variable value of renewable energy and demand-side efficiency resources. (University of California at Berkeley, 2015).

4. = Valentino, L., Valenzuela, V., Botterud, A., Zhou, Z. \& Conzelmann, G. System-Wide Emissions Implications of Increased Wind Power Penetration. Environ. Sci. Technol. 46, 4200-4206 (2012).

5. Cullen, J. Measuring the Environmental Benefits of Wind-Generated Electricity. Am. Econ. J. Econ. Policy 5, 107-133 (2013).

6. Kaffine, D. T., McBee, B. J. \& Lieskovsky, J. Emissions Savings from Wind Power Generation in Texas. Energy J. 34, 155-175 (2013).

7. Novan, K. Valuing the wind: renewable energy policies and air pollution avoided. Am. Econ. J. Econ. Policy 7, 291-326 (2015).

8. Chiang, A. C., Moore, M. R., Johnson, J. X. \& Keoleian, G. A. Emissions reduction benefits of siting an offshore wind farm: A temporal and spatial analysis of Lake Michigan. Ecol. Econ. 130, 263-276 (2016).

9. Kerl, P. Y. et al. New approach for optimal electricity planning and dispatching with hourly timescale air quality and health considerations. Proc. Natl. Acad. Sci. 112, 10884-10889 (2015).

10. Ryan, N. A., Johnson, J. X. \& Keoleian, G. A. Comparative Assessment of Models and Methods To Calculate Grid Electricity Emissions. Environ. Sci. Technol. (2016).

11. U.S. Environmental Protection Agency. eGRID 9th edition version 1.0, Year 2010 Summary Tables. (2014).

12. Zivin, J. S. G., Kotchen, M. J. \& Mansur, E. T. Spatial and temporal heterogeneity of marginal emissions: Implications for electric cars and other electricity-shifting policies. J. Econ. Behav. Organ. 107, 248-268 (2014).

13. Tamayao, M.-A. M., Michalek, J. J., Hendrickson, C. \& Azevedo, I. M. L. Regional Variability and Uncertainty of Electric Vehicle Life Cycle CO2 Emissions across the United States. Environ. Sci. Technol. 49, 8844-8855 (2015).

14. MacPherson, N. D., Keoleian, G. A. \& Kelly, J. C. Fuel Economy and Greenhouse Gas Emissions Labeling for Plug-In Hybrid Vehicles from a Life Cycle Perspective. J. Ind. Ecol. 16, 761-773 (2012).

15. National Solar Radiation Data Base. Typical Meteorological Year 3 (TMY) data set. (2012).

16. National Renewable Energy Laboratory. System Advisor Model, version 2015.6.30. (2015). 
17. Bolinger, M. \& Seel, J. Utility Scale Solar 2015: An Empirical Analysis of Project Cost, Performance, and Pricing Trends in the United States. (Lawrence Berkeley National Laboratory, 2016).

18. U.S. Environmental Protection Agency. Avoided Emissions and Generation Tool (AVERT). (2016).

19. Cooper, C. D. \& Alley, F. C. Air pollution control: A design approach. (Waveland Press, 2002).

20. U.S. Energy Information Administration, Monthly Energy Review, https://www.eia.gov/totalenergy/data, accessed March 1, 2017. (2017)

21. Barbose, G., Bird, L., Heeter, J., Flores-Espino, F. \& Wiser, R. Costs and benefits of renewables portfolio standards in the United States. Renew. Sustain. Energy Rev. 52, 523-533 (2015).

22. Barbose, G. et al. A retrospective analysis of benefits and impacts of US renewable portfolio standards. Energy Policy 96, 645-660 (2016).

23. Lyon, T. P. \& Yin, H. Why Do States Adopt Renewable Portfolio Standards?: An Empirical Investigation. Energy J. 31, 133-157 (2010).

24. Utility-Scale Solar 2015: An Empirical Analysis of Project Cost, Performance, and Pricing Trends in the United States. (2016).

25. Good, J. \& Johnson, J. X. Impact of inverter loading ratio on solar photovoltaic system performance. Appl. Energy 177, 475-486 (2016).

This article is protected by copyright. All rights reserved. 


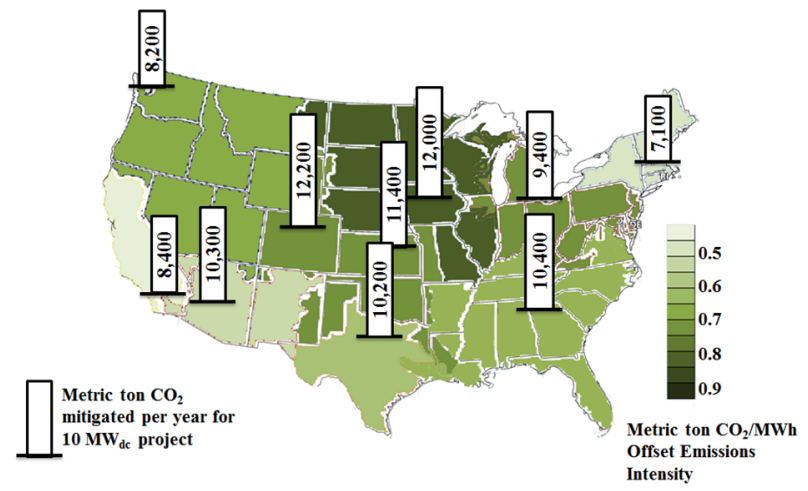

Abstract Art.tif

This article is protected by copyright. All rights reserved. 

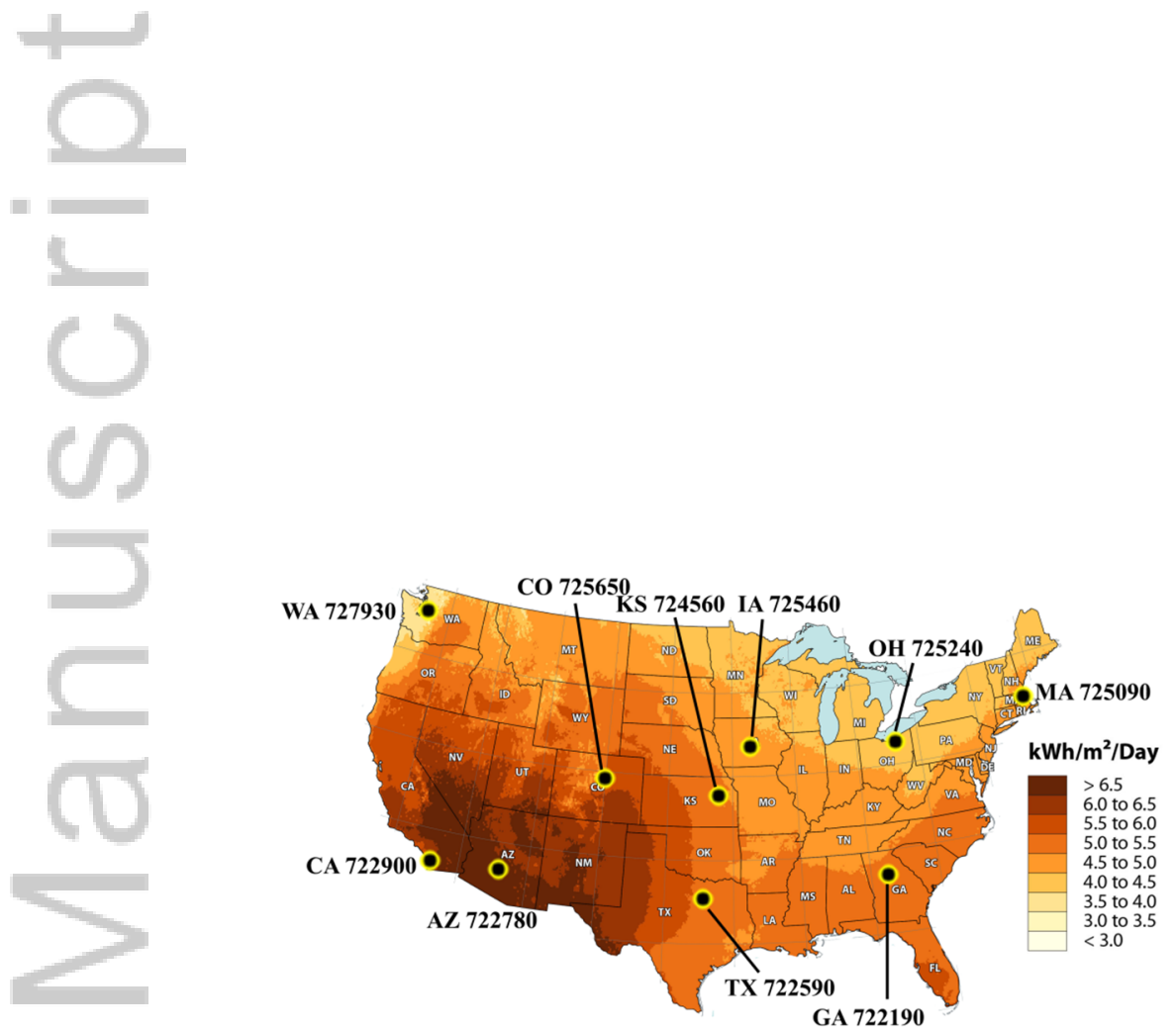

Fig 1.tif

This article is protected by copyright. All rights reserved. 


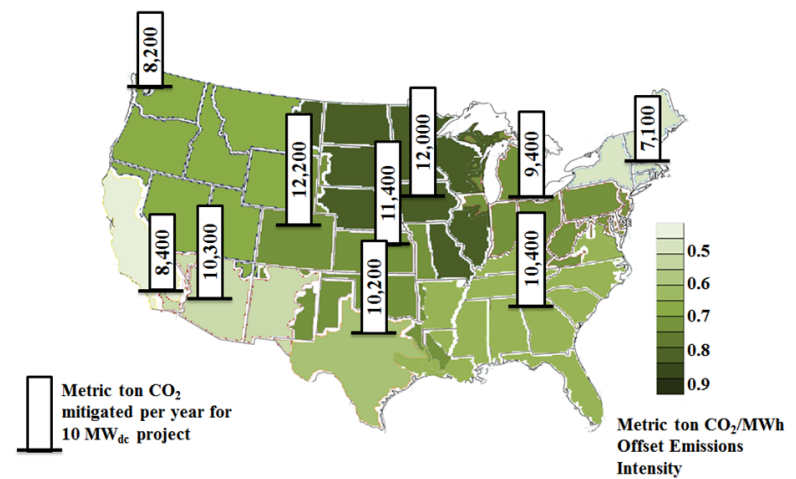

Fig 2a.tif

This article is protected by copyright. All rights reserved. 


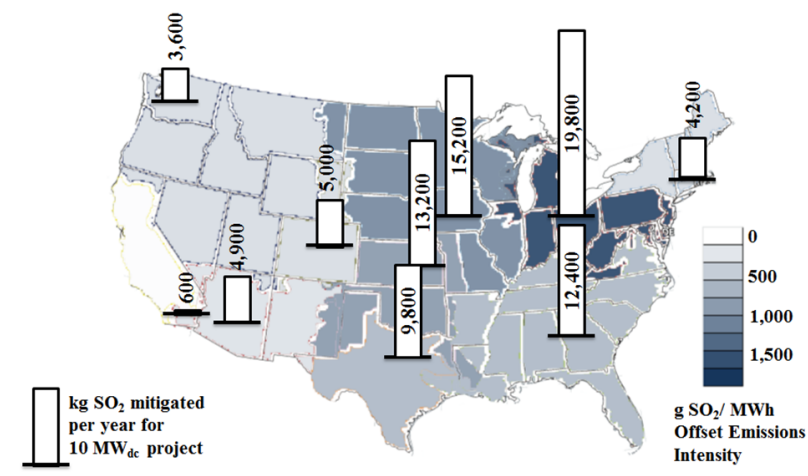

Fig 2b.tif

This article is protected by copyright. All rights reserved. 


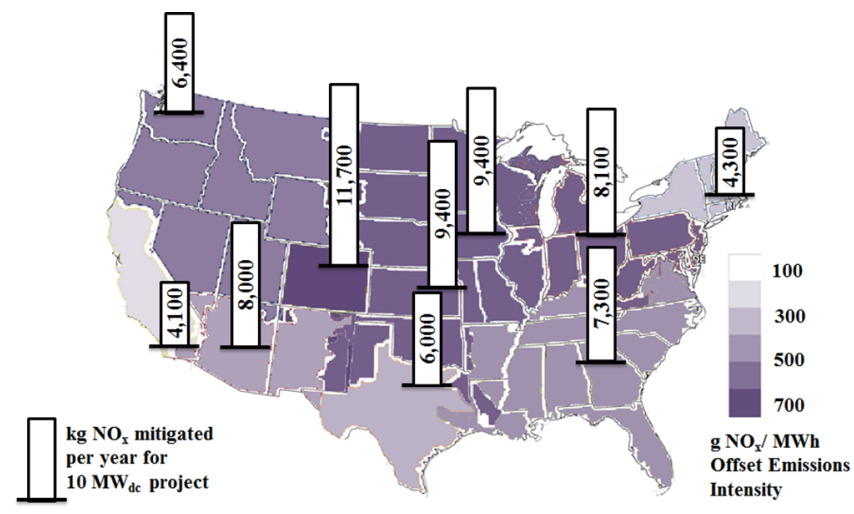

Fig 2c.tif

This article is protected by copyright. All rights reserved. 


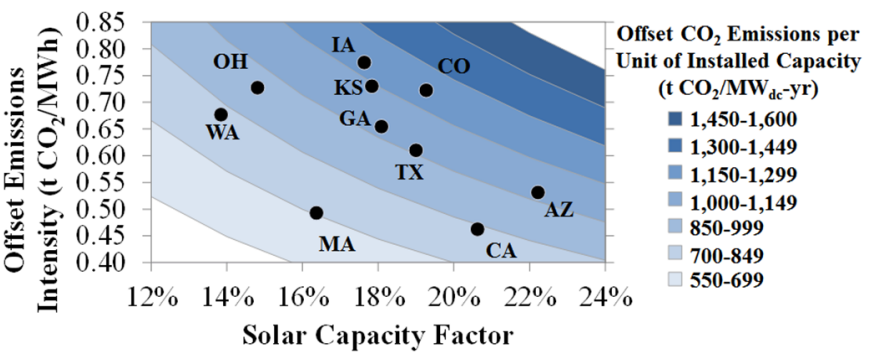

Fig 3a.tif

This article is protected by copyright. All rights reserved. 

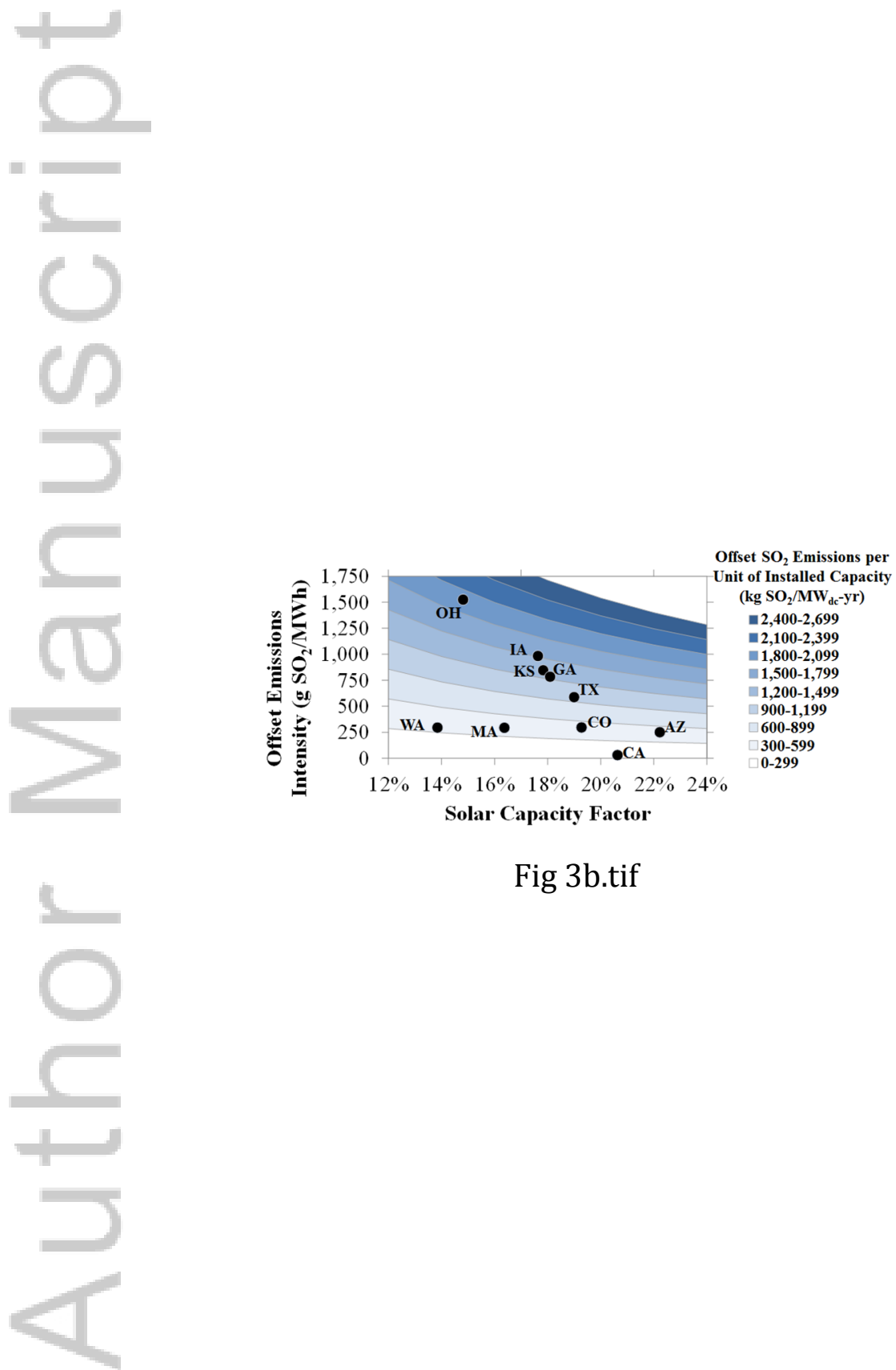

Fig 3b.tif

This article is protected by copyright. All rights reserved. 


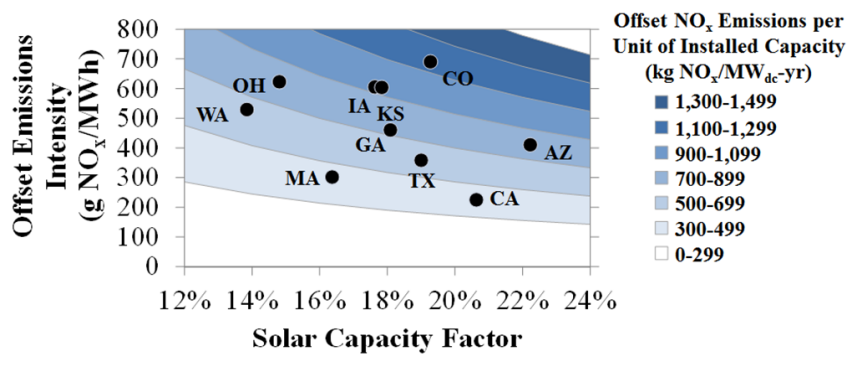

Fig 3c.tif

This article is protected by copyright. All rights reserved. 

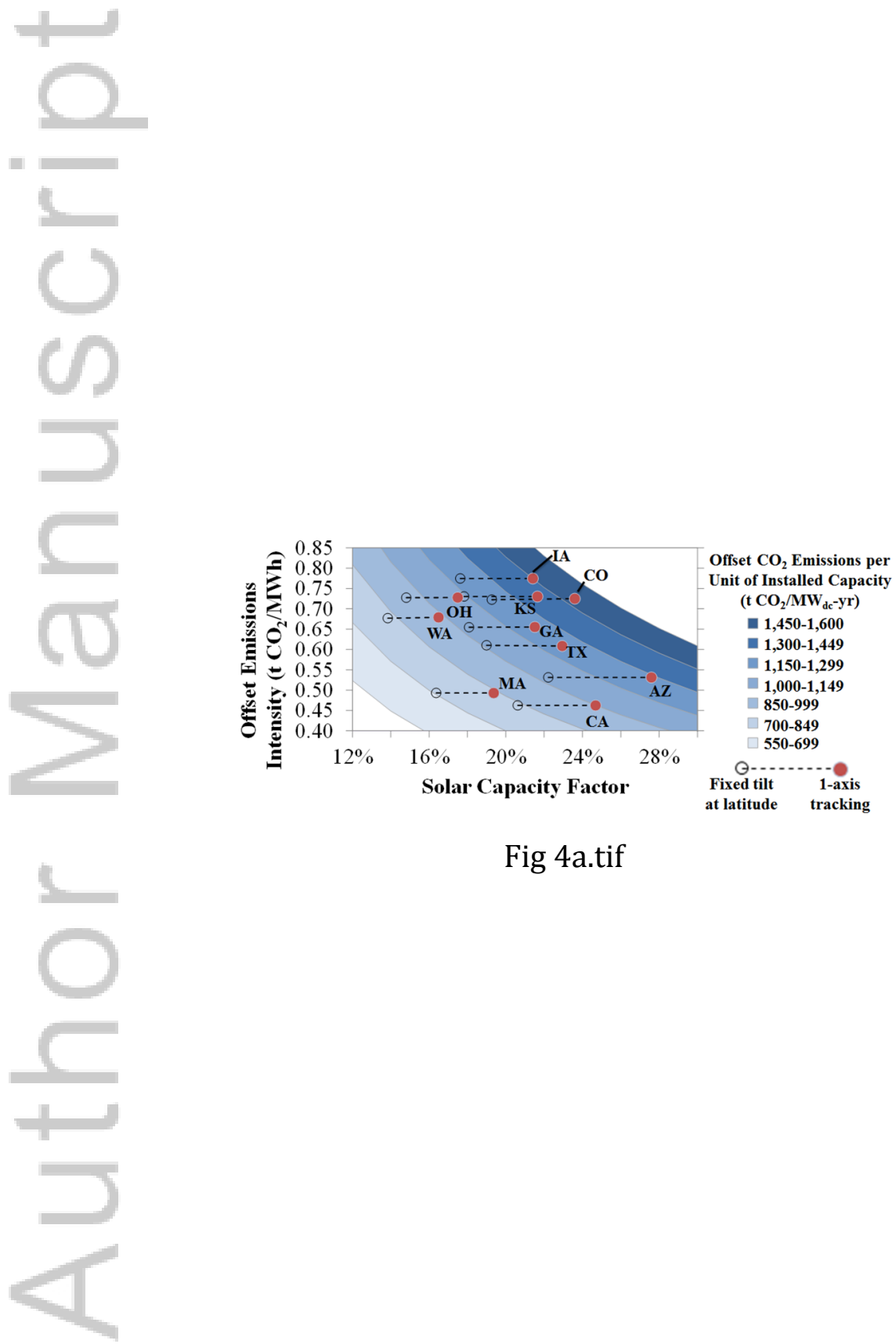

Fig 4a.tif

This article is protected by copyright. All rights reserved. 


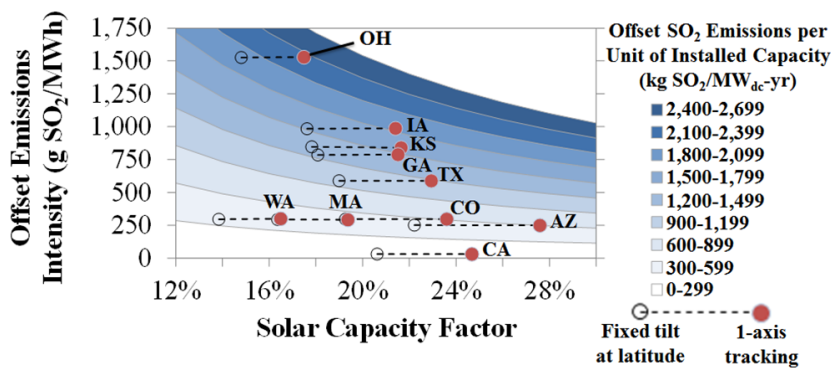

Fig 4b.tif

This article is protected by copyright. All rights reserved. 


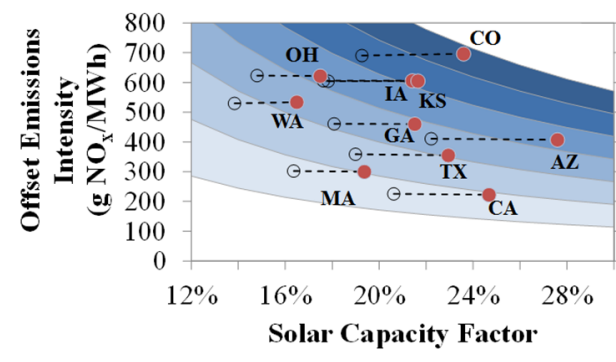

Fig 4c.tif
Offset $\mathrm{NO}_{\mathrm{x}}$ Emissions per $\left(\mathrm{kg} \mathrm{NO} \mathrm{O}_{\mathbf{x}} / \mathbf{M W}_{\mathrm{dc}}-\mathrm{yr}\right)$

- 1,300-1,499

- 1,100-1,299

무 $900-1,099$

- 700-899

$\square$ 500-699

300-499

0-299

Fixed tilt 1 -axis

at latitude tracking 


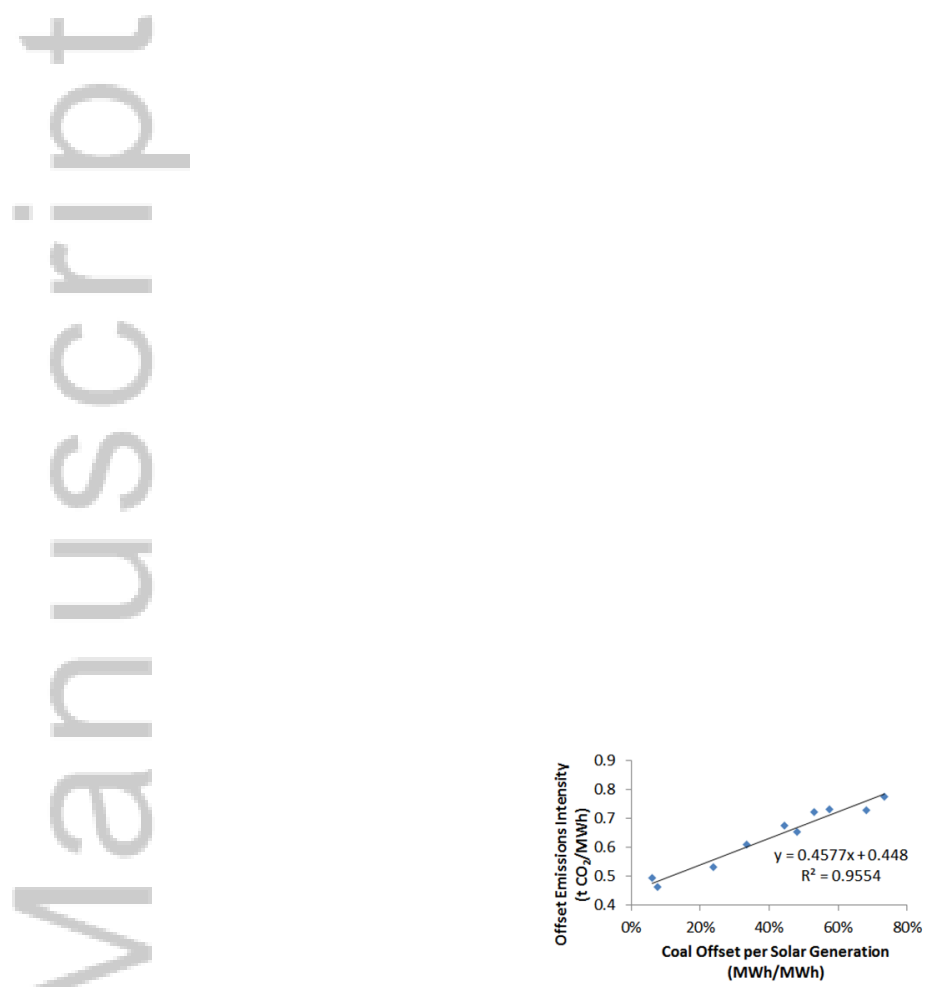

Fig 5a.tif

This article is protected by copyright. All rights reserved. 


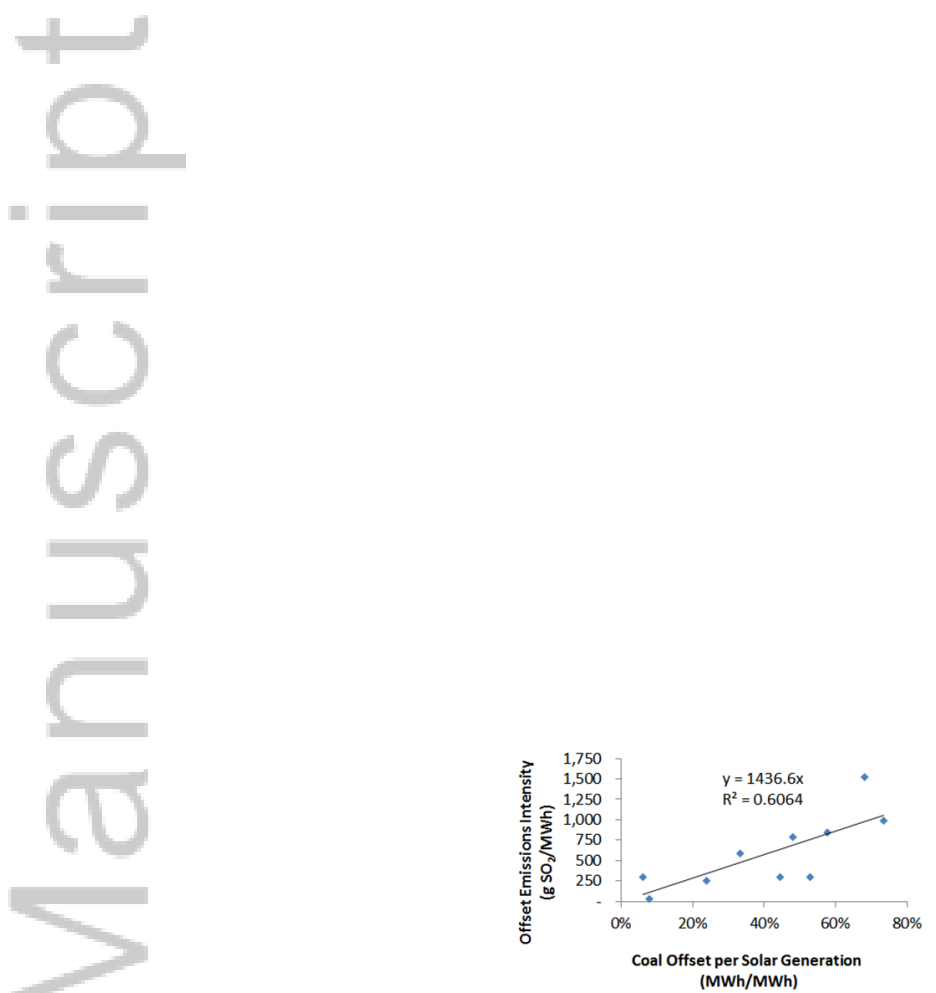

Fig 5b.tif

This article is protected by copyright. All rights reserved. 


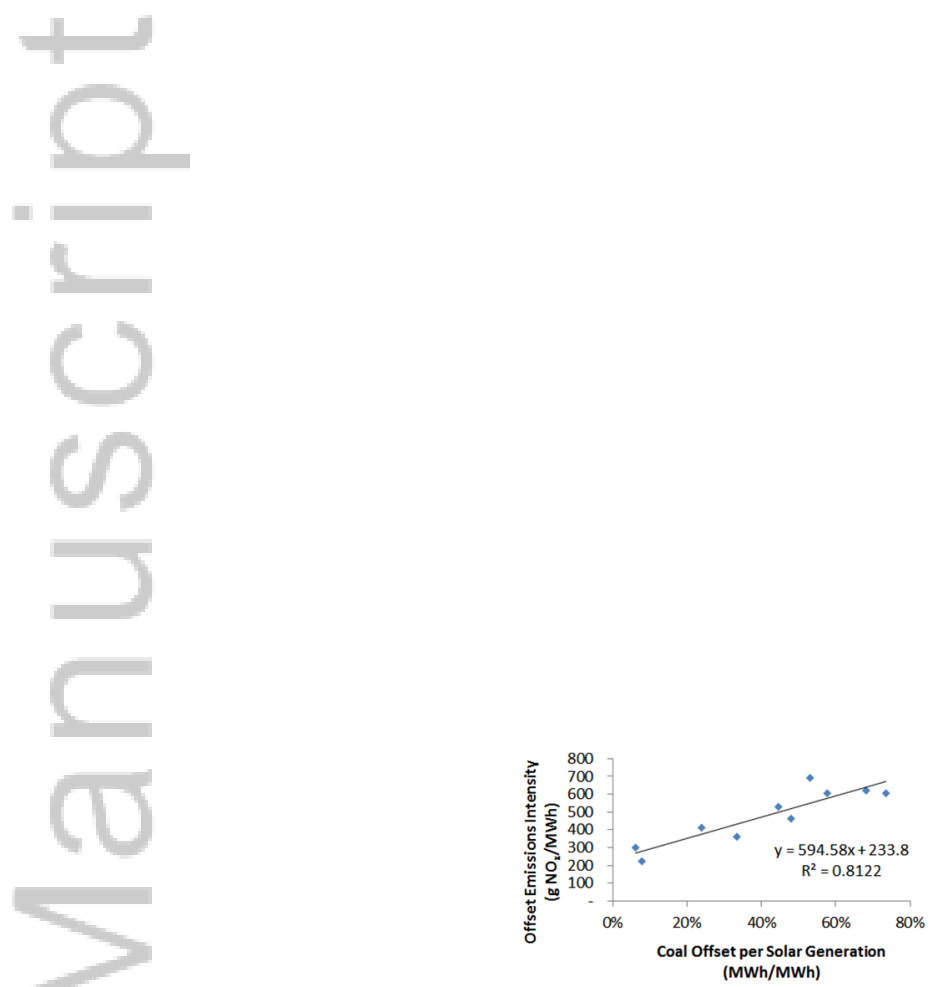

Fig 5c.tif

This article is protected by copyright. All rights reserved. 

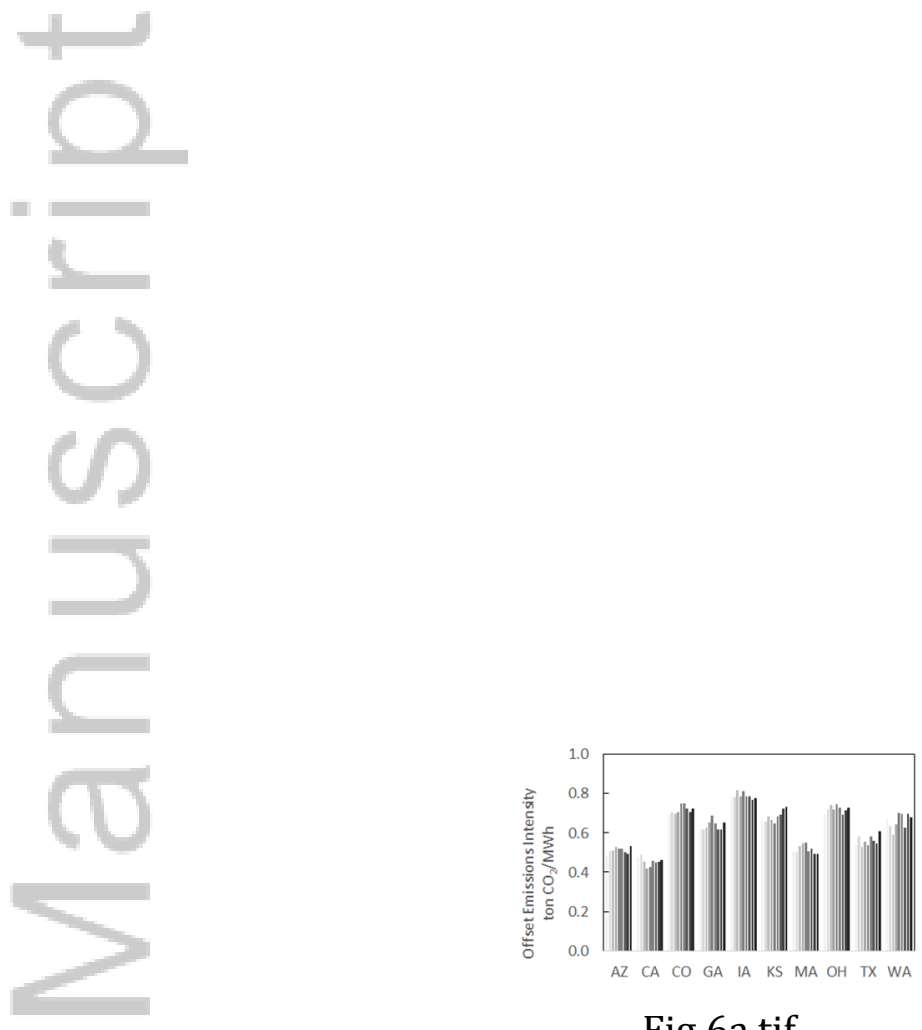

Fig 6a.tif

This article is protected by copyright. All rights reserved. 

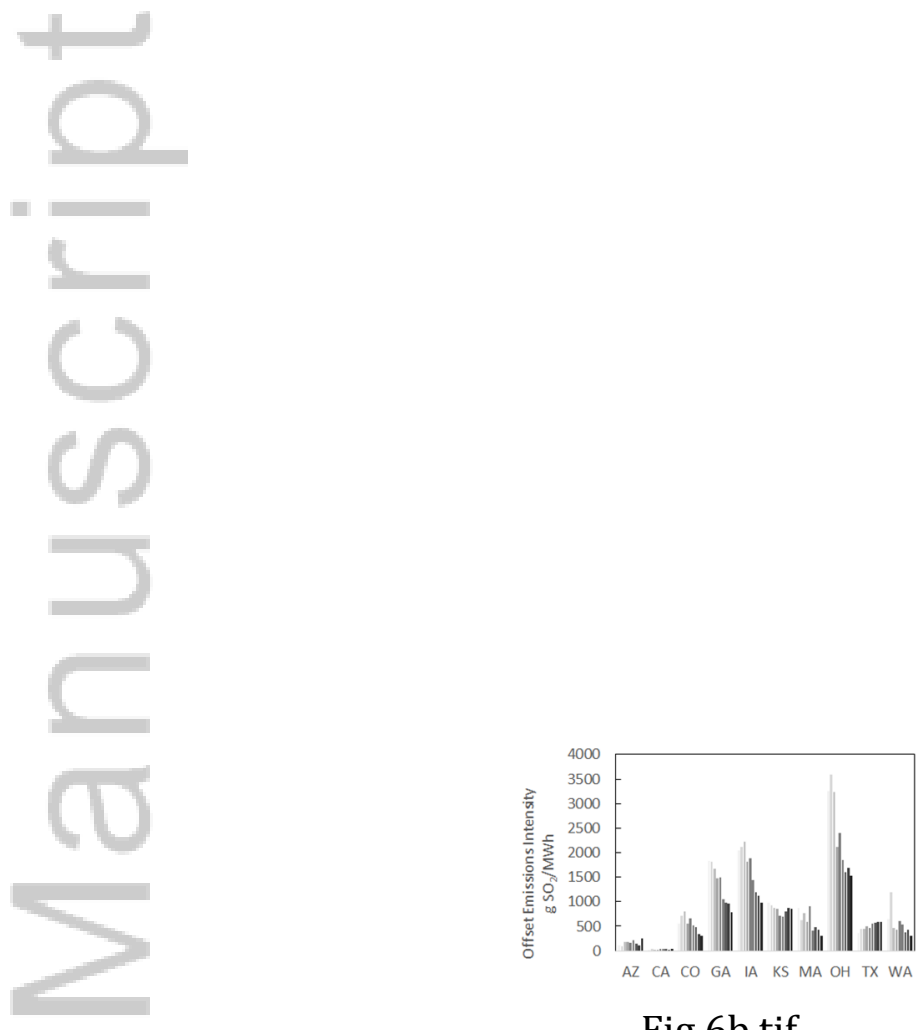

Fig 6b.tif

This article is protected by copyright. All rights reserved. 

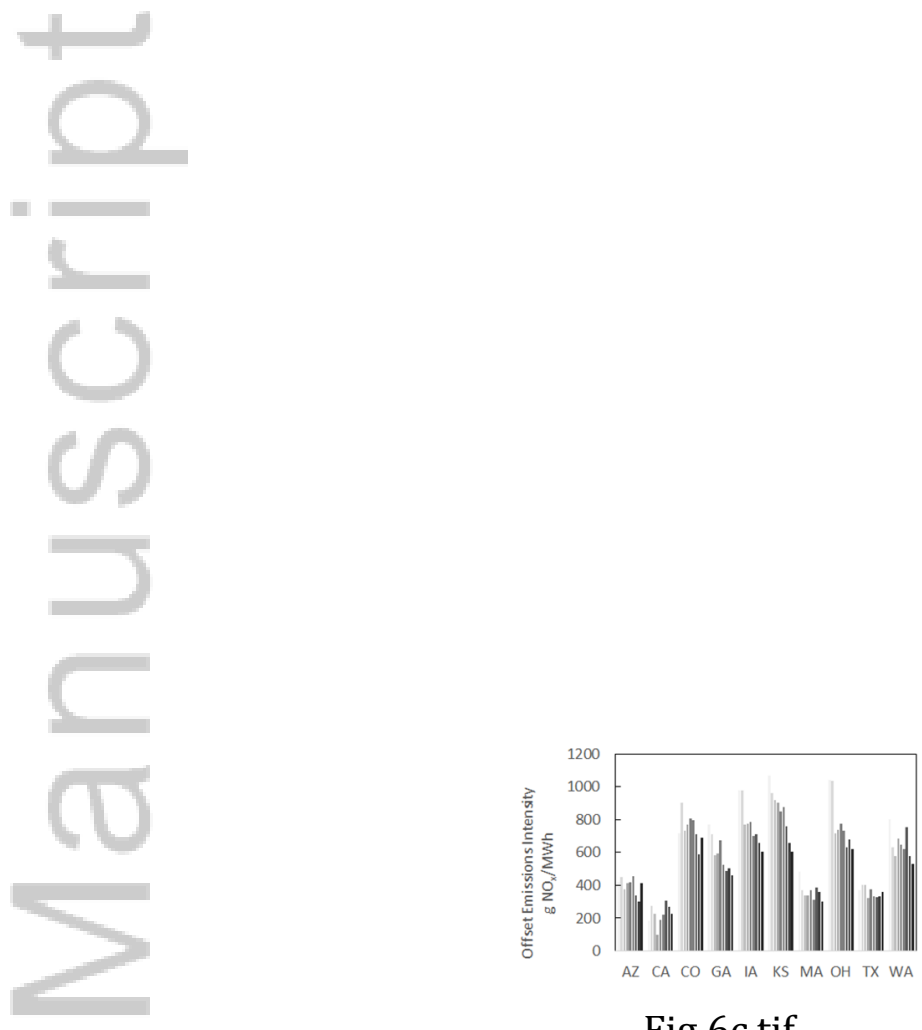

Fig 6c.tif

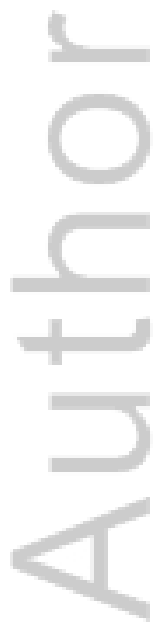

This article is protected by copyright. All rights reserved. 


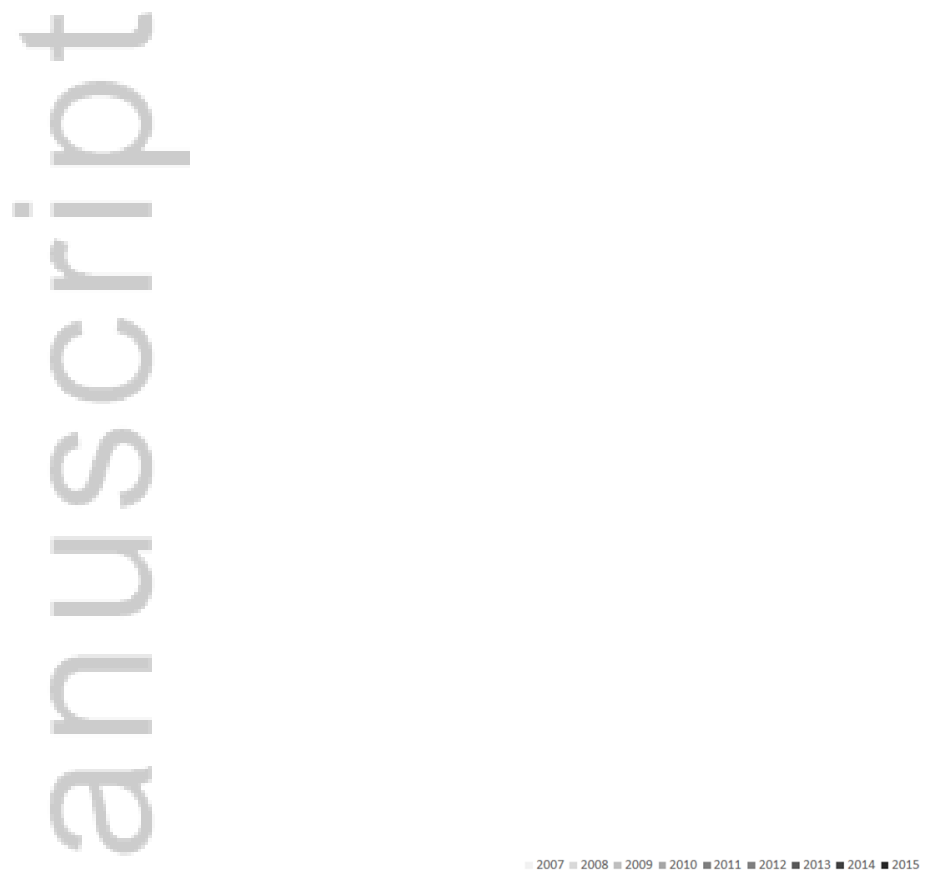

Fig 6-legend.tif

This article is protected by copyright. All rights reserved. 